PACS: $52.77 . \mathrm{Dq}$, 66.30.-h

\title{
INFLUENCE OF IONIC BOMBARDMENT ON THE PROCESSES OF NITRIDING DURING COMPLEX MODIFICATION OF STEEL SURFACE
}

\author{
V.A. Belous ${ }^{1}$, DYu.A. Zadneprovskiy ${ }^{1 *}$, DN.S. Lomino ${ }^{1}$, DI.S. Domnich ${ }^{1}$, T.I. Bevs ${ }^{2}$ \\ ${ }^{I}$ National Science Center "Kharkov Institute of Physics \& Technology" NSC KIPT \\ 61108, Kharkov, Academy street., 1 \\ ${ }^{2}$ AT «Турбоатом», 61037, Харьков, Московский проспект, 199 \\ *E-mail:yaz@kipt.kharkov.ua \\ 2 JSC "Turboatom", 61037, Kharkov, Moscowkiy av, 199 \\ Received 2 November 2018, accepted 23 November 2018
}

Ionic bombardment of the surfaces modified with the use of vacuum-arc technologies is a basic physical process for such modifications. Experiments were produced on plant of type "Bulat". In-process on nitriding of surfaces massive steel details (item of $25 X 1 M \Phi$ and $40 X)$ was investigated features of using of bombardment particles with different energy content. As bombarding particles ions of titan and molybdenum was use. This stage of ionic bombardment is related to cleaning of surface and heating of it to the necessary temperature. On the step of nitriding bombardment was carried out by the ions of nitrogen, generated in a two-stage discharge. For diagnostics of changes on the surface of standards and in the distance from it deep into metal, used X-ray fluorescence mass-analysis and produced measuring of hardness by means of device of Nanoindentor G200. The comparative measuring of relative concentrations of elements is executed in composition a surface became after bombardments different ions ( $T i$ or $M o$ ), and also the profiles of bedding of the implanted nitrogen and modified hardness in a metal are got. Features are educed in the results of nitriding of steel surface by the use of different sorts of ions. The photos of the transversal microsections got by means of optical metallography microscope of MMO 1600 showed differences in structural characteristics of the nearsurface layers by using the bombardments ions of titan and molybdenum. These differences are related to the high temperature in layers during bombardment the ions of molybdenum. The purpose of this work is conduction comparative experiments on the treatment of steel surfaces with accelerated ions of various metals with the subsequent analysis of the influence of such effects on the nitriding processes on these surfaces.

KEYWORDS: ionic bombardment, steel, nitriding, ions of titan and molybdenum.

\section{ВПЛИВ ІОННОГО БОМБАРДУВАННЯ НА ПРОЦЕСИ АЗОТУВАННЯ ПРИ КОМПЛЕКСНІЙ МОДИФІКАЦІЇ} ПОВЕРХНІ СТАЛІ

\author{
В.А. Білоус ${ }^{1}$, Ю.О. Задніпровський ${ }^{1}$, І.С. Домніч ${ }^{1}$, М.С. Ломіно ${ }^{1}$, Т.І. Бевз ${ }^{2}$
}

${ }^{1}$ Інститут фізики твердого тіла, матеріалознавства і технологій ННЦ ХФТІ 61108, Харків, вул. Академічна, 1

${ }^{2}$ АТ «Турбоатом», 61037, Харків, Московський проспект, 199

Іонне бомбардування поверхонь, які модифікуються з використанням вакуумно-дугових технологій, є основним фізичним процесом для таких модифікацій. Експерименти проводилися на установці типу "Булат. У роботі по азотуванню поверхонь масивних сталевих деталей (ст. $25 X 1 M \Phi$ і $40 X$ ) досліджені особливості використання в якості бомбардуючих часток іонів титану і молібдену, що мають різний енерговміст. Цей етап іонного бомбардування пов'язаний з очищенням поверхні i нагрівом iї до необхідної температури. На етапі азотування бомбардування здійснювали іонами азоту, що генеруються в двоступінчатому розряді. Для діагностики змін на поверхні зразків і на відстані від неї углиб металу, використали рентгенофлуоресцентний мас-аналіз і робили виміри твердості за допомогою приладу Nanoindentor G200. Виконані порівняльні виміри відносних концентрацій елементів у складі поверхні сталі після бомбардувань різними іонами (Ti або Mo), а також отримані профілі залягання заглибленого в метал азоту і модифікованої твердості. Виявлені особливості в результатах азотування сталевої поверхні при використанні різних сортів іонів. Фотографії поперечних шліфів, отриманих за допомогою оптичного металографічного мікроскопу МMO 1600, продемонстрували відмінності в структурних характеристиках приповерхневих шарів при бомбардуваннях іонами титану і молібдену. Ці відмінності пов'язані 3 підвищеною температурою в шарах при бомбардуванні іонами молібдену. Метою цієї роботи $є$ проведення порівняльних експериментів по обробці сталевих поверхонь прискореними іонами різних металів з подальшим аналізом діяння таких впливів на процеси азотування цих поверхонь.

КЛЮЧОВІ СЛОВА: іонне бомбардування, сталь, азотування, іони титану і молібдену.

\section{ВЛИЯНИЕ ИОННОЙ БОМБАРДИРОВКИ НА ПРОЦЕССЫ АЗОТИРОВАНИЯ ПРИ КОМПЛЕКСНОЙ МОДИФИКАЦИИ ПОВЕРХНОСТИ СТАЛИ \\ В.А. Белоус ${ }^{1}$, Ю.А. Заднепровский ${ }^{1}$, И.С. Домнич ${ }^{1}$, Н.С. Ломино ${ }^{1}$, Т.И. Бев $3^{2}$ \\ ${ }^{l}$ Институт физики твёрдого тела, материаловедения и технологий ННЦ ХФТИ, 61108, Харьков, ул. Академическая, 1 \\ ${ }^{2}$ АТ «Турбоатом», 61037, Харьков, Московский проспект, 199}

Ионная бомбардировка поверхностей, модифицируемых с использованием вакуумно-дуговых технологий, является основным физическим процессом для таких модификаций. Эксперименты производились на установке типа «Булат». В работе по азотированию поверхностей массивных стальных деталей (ст. $25 X 1 M \Phi$ и 40X) исследованы особенности использования в качестве бомбардирующих частиц ионов титана и молибдена, обладающих различным энергосодержанием. Этот этап ионной бомбардировки связан с очисткой поверхности и нагревом её до необходимой температуры. На этапе 
азотирования бомбардировку осуществляли ионами азота, генерированными в двухступенчатом разряде. Для диагностики изменений, происходящих на поверхности образцов и на расстоянии от неё вглубь металла, использовали рентгенофлуоресцентный масс-анализ и производили измерения твёрдости с помощью прибора Nanoindentor G200. Выполнены сравнительные измерения относительных концентраций элементов в составе поверхности стали после бомбардировок различными ионами ( $T$ i или $\mathrm{Mo}$ ), а также получены профили залегания внедрённого в металл азота и модифицированной твёрдости. Выявлены особенности в результатах азотирования стальной поверхности при использовании разных сортов ионов. Фотографии поперечных шлифов, полученных с помощью оптического металлографического микроскопа ММО 1600 , продемонстрировали отличия в структурных характеристиках приповерхностных слоёв при бомбардировках ионами титана и молибдена. Эти отличия связаны с повышенной температурой в слоях при бомбардировке ионами молибдена. Целью настоящей работы является проведение сравнительных экспериментов по обработке стальных поверхностей ускоренными ионами разных металлов с последующим анализом влияния таких воздействий на процессы азотирования этих поверхностей.

КЛЮЧЕВЫЕ СЛОВА: ионная бомбардировка, сталь, азотирование, ионы титана и молибдена.

В вакуумно-дуговых технологиях модификации поверхности деталей машин и инструмента, применяемых для улучшения различных физических и служебных характеристик, традиционно используется стадия, связанная с использованием ионной бомбардировки обрабатываемых изделий. На этой стадии в условиях остаточного вакуума $\left(P \sim 10^{-5}\right.$ Topp) и прикладывании к металлической поверхности отрицательного потенциала $(V \sim 1 \kappa B)$, её бомбардируют ускоренными ионами, являющимися продуктами эрозии расходуемых катодов. При этом, в качестве материала этих катодов могут быть использованы различные металлы. Обычно применяют те же материалы, которые участвуют и на последующих стадиях модификации, например, в осаждении защитных покрытий на основе соединений этих металлов с различными рабочими газами (нитридами, оксидами, карбидами и т.п.). Цель такой бомбардировки поверхности ионами металла состоит в очистке её от нежелательных загрязнений и в разогреве поверхности до необходимой температуры. В технологиях вакуумнодуговой обработки оба эти эффекта обеспечивают высокую степень адгезии осаждаемых покрытий к защищаемой поверхности металла.

При осаждении износостойких покрытий на изделия, представляющие собой пары трения, с целью снижения эффекта прилипания поверхностей, обычно используют различные составы упрочняющих покрытий. Так, например, при упрочнении деталей такой пары, входящих в состав блока парораспределения турбины $K-325$ производства АТ «Турбоатом», были использованы покрытия из нитридов титана и молибдена [1]. Эти покрытия осаждались на предварительно упрочнённую основу металла (стали $25 X 1 M \Phi$ или $40 X$ ) до глубин $\sim 150$ мкм, что достигалось на стадии ионного азотирования. Такая комбинированная обработка поверхности деталей (азотирование + осаждение покрытий) проводилась в условиях единого технологического процесса ионной модификации [2]. С помощью такой обработки существенно (в разы) повышена износостойкость деталей, входящих в состав пары трения.

Целью настоящей работы является проведение сравнительных экспериментов по обработке стальных поверхностей ускоренными ионами разных металлов с последующим анализом влияния таких воздействий на процессы азотирования этих поверхностей.

\section{РЕЗУЛЬТАТЫ ЭКСПЕРИМЕНТОВ И ИХ ОБСУЖДЕНИЕ}

В процессе разработки технологии вакуумно-дуговой комплексной обработки деталей нами использовались катоды из молибдена и титана. При этом ионная бомбардировка поверхности могла осуществляться как ионами этих металлов каждого в отдельности, так и при совместной работе Ti- и $M o$ катодов. Температуру нагрева образцов контролировали с помощью инфракрасного пирометра типа МX-4 с выводом излучения через окно из германия. Наблюдаемые на поверхности образцов отличия в результатах таких бомбардировок наглядно представлены на рис.1. Как видно из этого рисунка, поверхность исходного образца (его размеры 20х10х6мм) имеет следы некачественной полировки, которые после облучения ионами металлов, нивелируются, причем при бомбардировке ионами молибдена эрозия поверхности происходит гораздо интенсивнее, чем при бомбардировке ионами титана. Также эрозионные процессы зависят и от состава распыляемой стали. Это видно из сравнения результатов по распылению поверхности образцов двух марок сталей - 25X1MФ и 40X. Дозы облучения, используемые в этом эксперименте, одинаковы.

Распылительная способность ионов Мо выше, чем ионов $T i$ как за счёт их большей кинетической энергии $\left(E_{o}=58,9\right.$ эВ против 149 эВ[3]), приобретаемой при вылете из катодного пятна, так и ввиду большей величины среднего заряда этих ионов $\left(z=3,1\right.$ против 2,1[3]). Последнее обстоятельство согласно формуле $E_{i}=z e V$ приводит к повышению энергии ионов $E_{i}$ в дебаевском слое вблизи распыляемой поверхности, к которой по технологии приложен отрицательный потенциал $V$. (В нашем случае $V=1,2$ кВ). Бомбардировка ионами Мо приводит также к более быстрому набору образцом температуры по сравнению с бомбардировкой ионами титана. Заданный предел рабочей температуры во избежание возможного перегрева поверхности обеспечивался использованием ионной бомбардировки в импульсном режиме, когда во время паузы происходило выравнивание температуры между поверхностью и сердцевиной образца.

В распыляемом ионами поверхностном слое происходит явление, известное как ионное перемешивание, при котором часть бомбардирующих ионов оказывается замурованной в этом слое. 

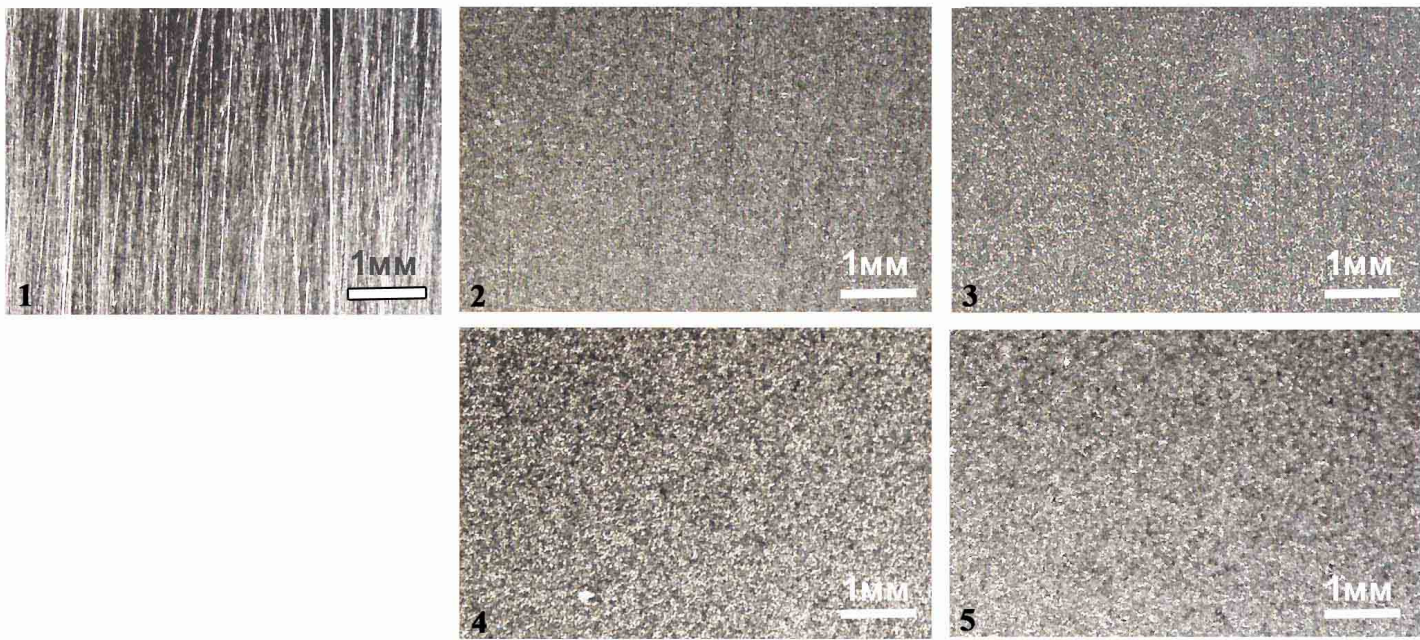

Рис. 1 Поверхность образцов после бомбардировки ионами $T i(2$ u 3) и ионами Mo (4 u 5) (материал: стали $25 X 1 M \Phi(2$ u 4$)$ и $40 X(3$ и 5)). Исходная поверхность стали -1 .

На рис. 2 представлены результаты исследования массового состава поверхности образцов ст. $25 X 1 M \Phi$. Эти измерения выполнены с помощью рентгено-флуоресцентного микроанализа на сканирующем электронном микроскопе $(S E M) J S M 7001 F$ и относятся только к сортам ионов, участвующих в ионной бомбардировке. Необходимо отметить, что исходная сталь не содержит титана, но содержит Мо в пределах 0,25 ат.\%. Как видно из этого рисунка, содержание молибдена в стали после её бомбардировки ионами Мо практически не изменилось, но при бомбардировке ионами $T i$ на поверхности образца отмечено заметное количество титана (до 0,8 ат.\%). В работе [4] показано, что бомбардировка поверхности стального образца ионами Ti приводит также к залечиванию существующих на этой поверхности микродефектов путём образования тонкой ( 1мкм) плёнки титана и к улучшению некоторых механических характеристик образца, в частности, конструкционной прочности.

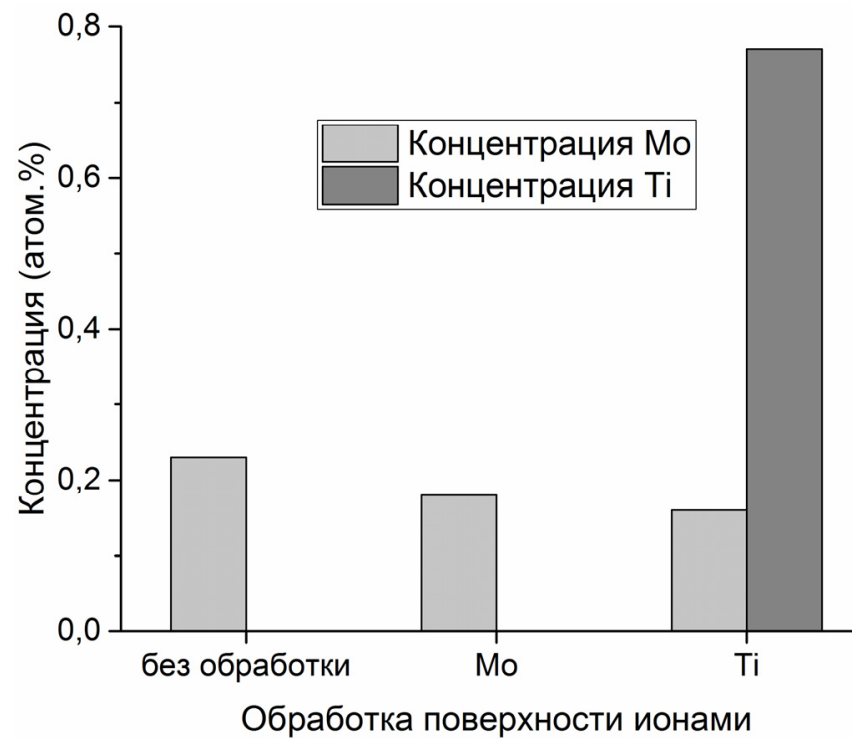

Рис.2. Результаты измерения относительного содержания титана и молибдена в поверхностном слое стали, подвергнутой бомбардировке ионами $T i$ и $M o$

Как уже указывалось выше, при бомбардировке ионами металла, после достижения на образцах температуры, необходимой для проведения стадии ионного азотирования данной марки стали, в вакуумной камере зажигался двухступенчатый вакуумно-дуговой разряд в атмосфере рабочего газа азота [5-6]. Параметры азотирования следующие: напряжение - $600 \mathrm{~B}$, плотность ионного тока на образцы - до $10 \mathrm{~mA} / \mathrm{cm}^{2}$, время азотирования - до 40 мин.

После проведения стадии азотирования с помощью микрозондовой диагностики исследовалось содержание азота в проазотированных образцах со стороны их поверхности, и по сечению приготовленных поперечных шлифов. Такие результаты получены как при бомбардировке поверхности образцов ионами $T i$, так и Мо. Результаты этих измерений представлены на рис. 3 и рис. 4.

На рис.4 также приведены результаты пошагового измерения твёрдости, выполненные с помощью прибора Nanoindentor $G 200$ при нагрузках $50 \mathrm{mN}$ и глубине индентирования $500 \mathrm{~nm}$. 


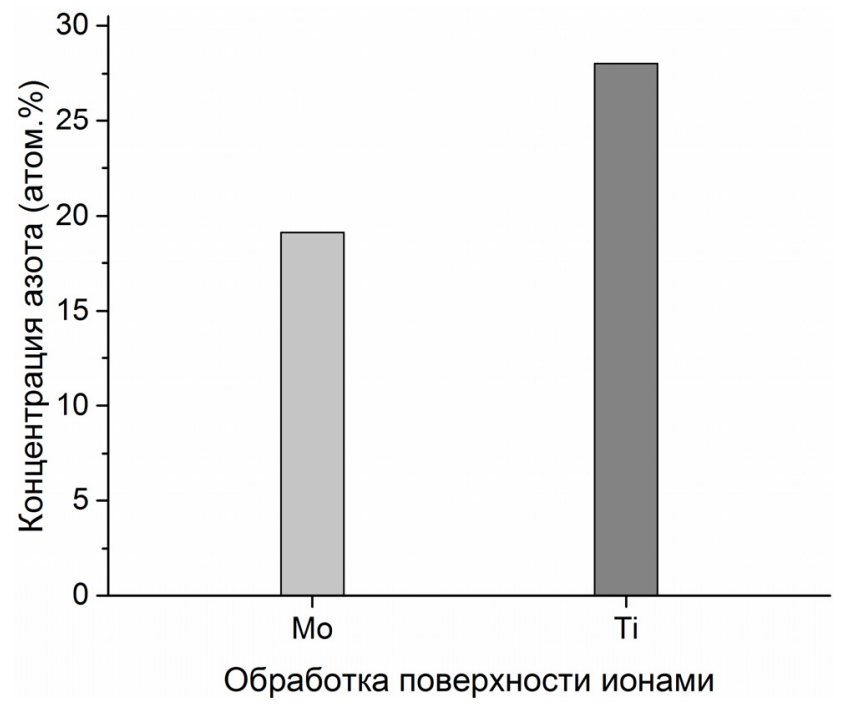

Рис. 3. Относительное содержание азота, измеренное с поверхности образцов при бомбардировке различными ионами

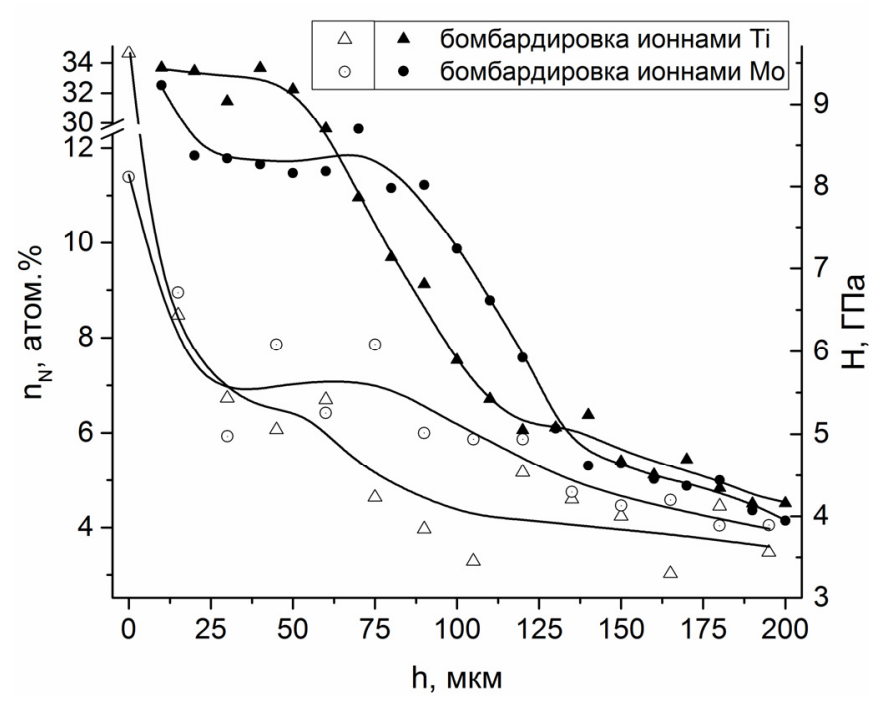

Рис. 4. Распределение относительного содержания азота и твёрдости по глубине от поверхности образца

Как следует из рис. 4, от сорта ионов (Ti или Mo), бомбардирующих поверхность на стадии её разогрева, зависят как распределения содержания внедрённого в образец азота, так и твёрдости слоя, модифицированного в результате этого внедрения. Некоторые различия в абсолютных значениях концентраций азота, полученных с поверхности (рис.3) и на шлифе вблизи поверхности (рис.4), связаны с особенностью методик, применяемых в этих измерениях. Результаты, представленные на рис. 3, получены при сканировании поверхности рентгеновским пучком по площади 100×100 мкм, а исследования по сечению шлифа (рис. 4) проведены пучком, диаметр которого порядка нескольких мкм. Поэтому упомянутые различия в концентрациях могут быть объяснены присутствием капельной составляющей бомбардирующего потока, попадающей в поле зрения пучка. При измерениях по площади присутствие на поверхности образца капель металла приводит к снижению значений относительного содержания азота. Такой эффект более выражен в случае бомбардировки поверхности образца ионами $T i$, нежели $M o$, поскольку капельная составляющая эрозии титанового катода превышает соответствующую величину для катода из молибдена [6].

Ход кривых на рис. 4 , демонстрирующих поведение относительного содержания внедрённого азота $n_{N}(h)$, характеризуется наличием участков резкого спада до значений $\sim 8 \%$ к глубине $h=25$ мкм, причём такой их спад от поверхности образца не зависит от сорта бомбардирующих ионов. Для случая бомбардировки ионами титана в диапазоне глубин 25 мкм $<h<200$ мкм имеет место плавный выход зависимости $n_{N}(h)$ к нулевым значениям концентрации. При этом поведение кривой твёрдости $H(h)$ модифицированного слоя в целом повторяет ход кривой $n_{N}(h)$. В случае бомбардировки ионами Мо в указанном диапазоне глубин наблюдается немонотонность спада зависимостей $n_{N}(h)$ и $H(h)$ с хорошо выраженным участком плато в диапазоне 25 мкм $<h<100$ мкм.

Для объяснения наблюдаемых на рис. 4 различий в характере поведения зависимостей концентраций азота по глубине от поверхности образца использованы фотографии поперечных шлифов образцов в исходном состоянии и прошедших стадию нагрева с помощью ионной бомбардировки разными сортами ионов с последующим азотированием в течение 40 мин (рис. 5).
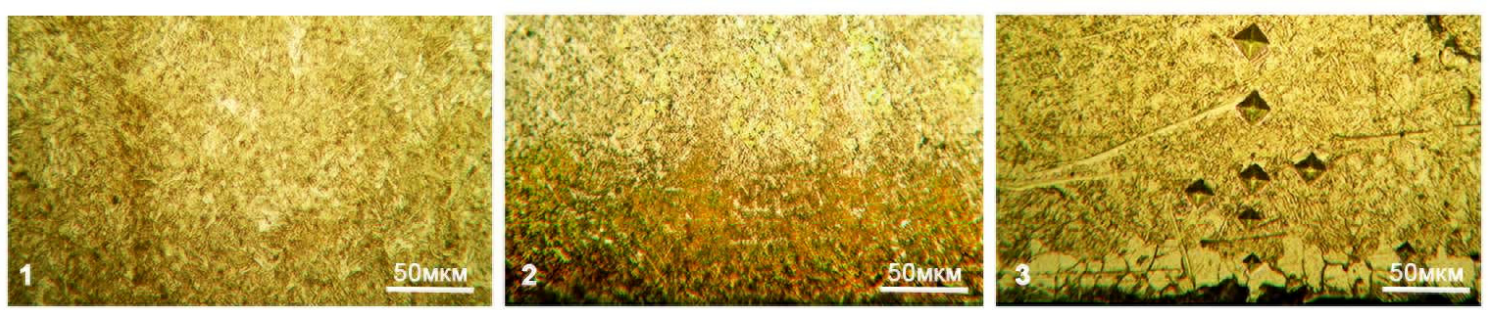

Рис.5 Фотографии шлифов образцов стали $25 X 1 M \Phi$ в исходном состоянии (1) и после проведенной ионной бомбардировки ионами $T i(2)$ и $M о$ (3) и стадии азотирования.

На фотографии поперечного шлифа стали, находящейся в исходном состоянии (1), видна однородная мелкозернистая структура с размытыми границами зерен. Она представляет собой феррито-перлитную смесь, что соответствует отожженному состоянию стали. Вследствие того, что бомбардировка образца осуществляется ионами $T i$ или $M o$, имеющими различное энергосодержание, формирование структурных характеристик в поверхностных слоях происходит под воздействием различных температур. В результате проведения процесса азотирования на глубинах до $h<120$ мкм микроструктура слоёв (на шлифах (2) и (3)) становится достаточно 
неоднородной. При этом в случае бомбардирующих ионов Мо на поверхности азотированного слоя (3) выявлены крупные (до 30мкм) зёрна феррита, что связано с нагревом поверхности образца до более высокой температуры по сравнению с бомбардировкой ионами Ti. На глубинах $h>120$ мкм исходная структура стали не претерпевает изменений.

Различие в модифицированных структурах поверхности образцов, прошедших стадию азотирования, может объяснить и наблюдаемые на рис. 4 отличия в профилях распространения азота вглубь металла для обоих вариантов бомбардировки - экспоненциальная зависимость для $T i$ и более сложная, немонотонная, для Мо. В самом деле, структура азотируемой стали с крупноразмерными зёрнами, распространённая на бо́льшую глубину от поверхности, и с развитыми границами зёрен предполагает наличие дополнительного канала, кроме канала объёмной термодиффузии, для продвижения азота вдоль этих границ.

Использование ионов молибдена для очистки и нагрева модифицируемой поверхности позволяет сократить время этих процессов по сравнению с бомбардировкой ионами титана. Однако при этом возможен нежелательный перегрев поверхности массивной детали на большую глубину. При работе с такими деталями рекомендовано применение бомбардировки в импульсном режиме, когда во время паузы происходит выравнивание температуры между поверхностью и сердцевиной образца.

\section{ВЫВОДЫ}

Технология комбинированного упрочнения (покрытие + азотирование основы) рабочих поверхностей деталей устройств отработана для случая полномасштабных узлов паровой турбины. Показано, что на стадии азотирования профили распространения азота вглубь металла и, соответственно, модифицированной твёрдости зависят от условий при бомбардировке ионами с различным энергосодержанием.

\section{ORCID IDs}

Yu.A. Zadneprovskiy (D) https://orcid.org/0000-0003-2754-4051, N.S. Lomino (D) https://orcid.org/0000-0002-5333-3867, I.S. Domnich (D) https://orcid.org/0000-0002-3276-2435

\section{СПИСОК ЛИТЕРАТУРЫ}

[1]. V.A. Belous, I.G. Yermolenko, Yu.A. Zadneprovsky, N.S. Lomino, Problems of Atomic Science and Tecnology. 4(104), 93-99 (2016). (in Russian)

[2]. V.A. Belous, Yu.A. Zadneprovsky, M.G. Ischenko, G.I. Ischenko, N.S. Lomino, in: ВИТТ-2017: Maтериаль 12-ц̌ Международной конференции «Взаимодействие излучения с твёрдым телом» [IRS-2017: Materials of the 12th International Conference on the Interaction of Radiation with Solids] (Belarusian State University, Minsk, 2017), pp. $367-370$. (in Russian)

[3]. A. Anders, Cathodic Arcs (Springer Science + Business Media, LLC, 2008), p. 514, doi: 10.1007/978-0-387-79108-1_8

[4]. I.A. Ponomarenko, I.S. Tatarkina and I.V. Doshchechkina, Bulletin of Kharkov National Automobile and Highway University. 51, 126-129 (2010). (in Ukrainian)

[5]. L.P. Sablev, N.S. Lomino, R.I. Stupak, A.A. Andreev, A.M. Chikryzhov, in: ОТTOM-6, Материалы 6-ой междунар. конференции «Оборудование и технологии термической обработки металлов и сплавов» [Materials of the 6th International Conference on the Equipment and Technologies for Heat Treatment of Metals and Alloys] (NSC KIPT, Kharkov, 2005), 2, pp.159-169. (in Russian)

[6]. V.A. Belous, Yu.A. Zadneprovsky, I.G. Yermolenko, N.S. Lomino, in: Ресурс-2015: Збірник наукових статей, Цільова комплексна програма НАН України «Проблеми ресурсу і безпеки експлуатаиії конструкцій, споруд $і$ машин» [Rеsоuгсе2015: Collection of scientific articles, Target complex program of NAS of Ukraine "Problems of the Resource and Safety of the Exploitation of Constructions, Structures and Machines], (IES them. Paton NAS of Ukraine, Kiev, 2015, pp. 247-255. (in Ukrainian)

[7]. I.I. Aksenov, I.I. Konovalov, E.E. Kudryavtseva and V.M. Khoroshich, JTF. 54(8), 1530-1533 (1984). (in Russian) 